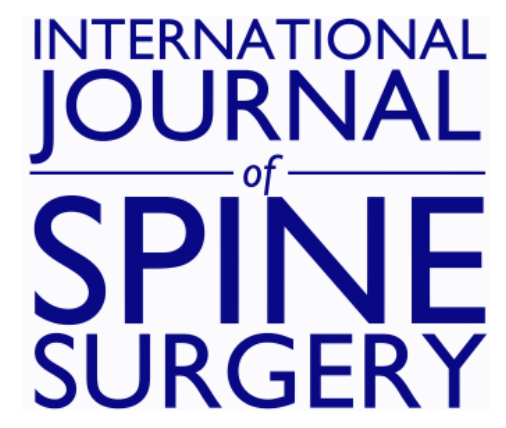

\title{
Quantitative evaluation of the lumbosacral sagittal alignment in degenerative lumbar spinal stenosis
}

Serik K. Makirov, Andrew A. Yuz, Mohammed T. Jahaf and Anastasia A. Nikulina

Int J Spine Surg 2015, 9 ()

doi: https://doi.org/10.14444/2068

http://ijssurgery.com/content/9/68

This information is current as of April 26, 2023.

Email Alerts Receive free email-alerts when new articles cite this article. Sign up at:

http://ijssurgery.com/alerts

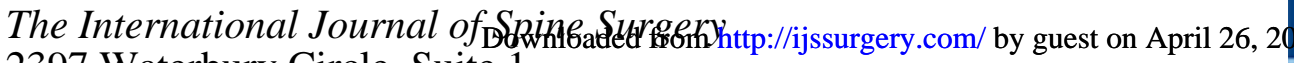
2397 Waterbury Circle, Suite 1,

Aurora, IL 60504, Phone: +1-630-375-1432

(C) 2015 ISASS. All Rights Reserved. 


\section{Quantitative evaluation of the lumbosacral sagittal alignment in degenerative lumbar spinal stenosis}

Serik K. Makirov, MD, ${ }^{1}$ Andrew A. Yuz, MD, ${ }^{1}$ Mohammed T. Jahaf, MD, ${ }^{1}$ Anastasia A. Nikulina, $B S^{2}$

${ }^{1}$ Traumatology, RMAPE, Moscow, Russia 2Bauman Moscow State Technical University, Moscow, Russia

\section{Abstract}

Goal of the study

This study intends to develop a method of quantitative sagittal balance parameters assessment, based on a geometrical model of lumbar spine and sacrum.

\section{Methods}

One hundred eight patients were divided into 2 groups. In the experimental group have been included 59 patients with lumbar spinal stenosis on L1-5 level. Forty-nine healthy volunteers without history of any lumbar spine pathlogy were included in the control group. All patients have been examined with supine MRI. Lumbar lordosis has been adopted as circular arc and described either anatomical (lumbar lordosis angle), or geometrical (chord length, circle segment height, the central angle, circle radius) parameters. Moreover, 2 sacral parameters have been assessed for all patients: sacral slope and sacral deviation angle. Both parameters characterize sacrum disposition in horizontal and vertical axis respectively.

\section{Results}

Significant correlation was observed between anatomical and geometrical lumbo-sacral parameters. Significant differences between stenosis group and control group were observed in the value of the "central angle" and "sacral deviation" parameters. We propose additional parameters: lumbar coefficient, as ratio of the lordosis angle to the segmental angle (Kl); sacral coefficient, as ratio of the sacral tilt (ST) to the sacral deviation (SD) angle (Ks); and assessment modulus of the mathematical difference between sacral and lumbar coefficients has been used for determining lumbosacral balance (LSB). Statistically significant differences between main and control group have been obtained for all described coefficients ( $p=0.006, p=0.0001, p=0.0001$, accordingly). Median of LSB value of was 0.18 and 0.34 for stenosis and control groups, accordingly.

\section{Conclusion}

Based on these results we believe that that spinal stenosis is associated with an acquired deformity that is measureable by the described parameters. It's possible that spinal stenosis occurs in patients with an LSB of 0.2 or less, so this value can be predictable for its development. It may suggest that spinal stenosis is more likely to occur in patients with the spinal curvature of this type because of abnormal distribution of the spine loads. This fact may have prognostic significance for develop vertebral column disease and evaluation of treatment results.

KEYWORDS: SAGITTAL LUMBOSACRAL BALANCE, LUMBAR LORDOSIS, LORDOSIS ANGLE, LUMBOSACRAL SAGITTAL ALIGNMENT

\section{Introduction}

Bipedalism allowed human to achieve intellectual, technological and social development. However, these changes became possible with a huge morphological adaptation of the skeleton, in particular, the lower extremities, pelvis and spine. Pelvis, in fact, is a key element of all these transformations. It's a free base and is exposed to the weight of the upper por- tion of the body as well as floor reaction force that is transmitted through the head of hip joints. In parallel with adaptations of the pelvis, the appearance of the spine curvature made it possible to achieve reduction of the stress load on the musculoligamentous structures and of the muscles contraction force required for the sagittal alignment maintaining. ${ }^{1}$

Lumbar lordosis is a key component in the formation 
of posture in men that implicated great interest in both clinicians and researchers for many years. Despite this parameter widespread using in assessment of postural disorders, many questions related to the measurement of lumbar lordosis, still remain unanswered. Many trials have demonstrated growing recognition of functional and clinical significance of lumbar lordosis..$^{2-6}$

The wide variety of the thoracic and lumbar curves values $(50 \mathrm{~mm}$ spread for C7 - S1sagittal deviations in healthy patients in upright position) have been corresponded as accepted criteria of the sagittal balance. ${ }^{7,8}$ This fact greatly complicates the research of the spine or the achievement of surgeons, researchers, clinicians and patients' similar purposes in the formation of an optimal posture. ${ }^{9}$

The goal of this study - developing a method of quantitative evaluation of the sagittal lumbosacral balance, based on geometrical parameters of lumbar spine and sacrum.

\section{Materials and Methods}

One hundred and eight patients divided into 2 groups have been included in the study. In the main group 59 patients (41 women (69.5\%), 18 men $(30.5 \%)$ ) in mean age 58.8 years with lumbar spinal stenosis on L1-L5 level have been included. In the control group - 49 volunteers (37 women (75.5\%), 12 men (24.5\%)) in mean age 48.1 years without natural history of spine diseases. All patients underwent MRI in supine position.

Lumbar lordosis angle - angle of lumbar curve wherein an upper limit of the angle is the upper endplate of the L1 body, lower - endplate of S1 body. A line (c) was constructed from the upper front angle of L1 vertebra (point A) to the the upper front angle of $\mathrm{S} 1$ vertebra (point B). Pass a perpendicular $(\mathrm{h})$ from the center of the chord to the ventral surface of the vertebral column (Figure 1). We assumed that the line (c) to be a chord of the circle and the perpendicular (h) is the height of the circle segment. Knowing a height of the segment and a chord length then, a circle radius ( $r$ can be calculated by the formula: $r=(h / 2)+\left(c^{2} /(8 h)\right)(1)$

where $\mathrm{r}$ - circle radius, $\mathrm{h}$ - segment height, $\mathrm{c}$ - chord length.

Knowing the radius of the circle, the central angle can be calculated by the formula:

$\alpha=2 \arcsin (c /(2 r))(2)$

where $\alpha$ - central angle, $\mathrm{c}$ - chord length, $\mathrm{r}$ - circle radius.

Then, a circle arc length can be calculated by formula:

$L=\alpha r(3)$

where $\mathrm{L}$ - circle arc length, $\alpha$ - central angle, $\mathrm{r}$ - circle radius.

Figure 1 shows an example of similar calculations. As one can see, the lumbar lordosis ideally matches the circle arc defined this way.

Because of parameters $c, h, r, \alpha$ and $L$ are related by means of circle geometry, only one of these variables therefore should be used in statistical analysis - the central angle value $(\alpha)$ in our study. All angular val-

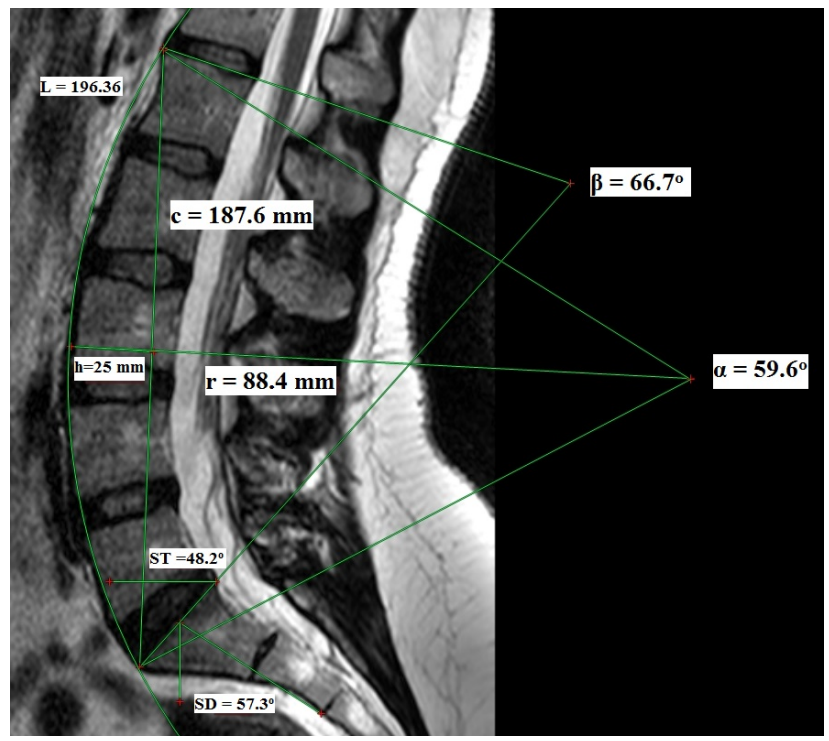

Fig. 1. Lumbosacral sagittal parameters. $L$ - circle arc length; $\alpha$ - central angle; $\beta$ - lordosis angle; $c$ - chord length; $r$ - circle radius; $h$ - segment height. ST - sacral tilt; SD - sacral deviation. 
ues have been expressed in degrees for the statistical analyses. So, the formula for calculation the central angle is:

$\alpha=(2 \arcsin (c /(2 r))) / 0.017(4)$

For the central angle value calculation therefore only two additional parameters should be measure by physician on MRI images: the segment height (h) and chord length (c). Also, for all patients' next lumbo-sacral anatomical parameters has been determined: a lordosis angle, Sacral Tilt and Sacral Deviation. The lordosis angle has been determined as angle between the superior endplate of L1 and the superior endplate of S1; sacral tilt (ST) - as angle between the upper endplate of $S 1$ and a vertical axis of the frame in supine position (analog Sacral Slope for upright position); sacral deviation (SD) - the angle between horizontal axis and the line from midpoint of the upper endplate of $S 1$ to the ventral surface of the S2/S3 disc. Graphical mapping of the measured parameters is presented in Figure 1.

Thus, for the all patients next parameters have been determined: lordosis angle, segment height, chord length, Sacral Tilt, and Sacral Deviation.

To describe lumbosacral sagittal alignment we use the ratio between angular values of one anatomical region:

1. Ratio of lordosis angle to the segmental angle (Lumbar coefficient):

$K_{l}=\beta / \alpha(5)$

This ratio describes relation between the angle of lordosis and central angle. In the other words: between the anatomical and geometrical angular values in the sagittal lumbar spine;

2. Ratio of Sacral Tilt to Sacral Deviation (Sacral coefficient):

$K_{s}=(S T) /(S D)(6)$

This ratio describes an equilibrium position of the sacrum in the sagittal plane frame.
3. We introduced a parameter, "lumbo-sacral balance," (LSB) that corresponds to the absolute difference between Sacral and Lumbar coefficients:

$L S B=\left|K_{s^{-}} K_{l}\right|(7)$

Measurements were performed in RadiAnt DICOM Viewer (Medixant, Poland). Measurement values have been introduced in Microsoft Excel 2010 (Microsoft, USA), where the remaining parameters were calculated using formulas 1 and 4-7. Statistical analysis of all data has been performed in IBM SPSS Statistics Version 19 (SPSS, IBM, USA).

\section{Results}

Descriptive statistics of all angular variables for the both groups are presented in Table 1 . The results of the Pearson's correlation analysis are presented in Table 2. For statistical analysis Mann-Whitney Ucriteria has been used (Table 3 ). As one can see from the obtained data, significant differences $(\mathrm{p}<0.05)$ between 2 groups are observed for central angle $(\alpha)$ and Sacral Deviation (SD). Also from Table 2, one can see statistical significant correlation between the determined anatomical and geometrical lumbo-sacral parameters.

Descriptive statistics for $\mathrm{K}_{\mathrm{s}}, \mathrm{K}_{1}$ and LSB for both groups are presented in Table 4. For compare the value of the coefficients in main and control group, we similarly used Mann-Whitney U-criteria. Range and statistics of criteria presented in Table 5.

\begin{tabular}{|c|c|c|c|c|c|c|c|c|c|}
\hline & & \multicolumn{4}{|c|}{ Main Group } & \multicolumn{4}{|c|}{ Control Group } \\
\hline & & $\alpha$ & $\beta$ & ST & SD & $\alpha$ & $\beta$ & ST & SD \\
\hline \multicolumn{2}{|l|}{$\mathrm{N}$} & \multicolumn{4}{|r|}{59} & \multicolumn{4}{|r|}{49} \\
\hline \multicolumn{2}{|c|}{$\begin{array}{l}\text { Mean Std. Er- } \\
\text { ror }\end{array}$} & 2.54 & 1.76 & 1.27 & 1.02 & 2.29 & 1.46 & 1.02 & .93 \\
\hline \multicolumn{2}{|l|}{ Median } & 55.39 & 49.90 & 39.60 & 43.80 & 41.41 & 47.80 & 39.30 & 50.90 \\
\hline \multicolumn{2}{|c|}{ Std. Deviation } & 19.57 & 13.55 & 9.73 & 7.82 & 16.01 & 10.24 & 7.11 & 6.53 \\
\hline \multicolumn{2}{|l|}{ Variance } & 381.30 & 182.69 & 94.61 & 61.10 & 256.45 & 104.84 & 50.61 & 42.61 \\
\hline \multirow{2}{*}{ Percentile } & 25 & 41.27 & 36.50 & 33.00 & 40.00 & 32.08 & 42.95 & 35.25 & 46.10 \\
\hline & 75 & 71.42 & 58.00 & 46.00 & 50.10 & 59.37 & 59.20 & 45.00 & 53.40 \\
\hline
\end{tabular}

Downloaded from http://ijssurgery.com/ by guest on April 26, 2023 


\section{Discussion}

Lumbar lordosis is a ventral orientated curve of the lumbar spine, which has been formed due to the wedge shape of intervertebral discs and the vertebral bodies. ${ }^{10,11}$ The form of the lumbar lordosis is equally influenced by the shape of the vertebral bodies and intervertebral discs; each of these structures account for about $50 \%$ of the variation of the angle of lordosis in adults. ${ }^{12,13}$ Lumbar lordosis is usually described by the anatomical parameter "lordosis angle." A strong correlation between the lordosis angle and other postural variables has been described in the literature. A

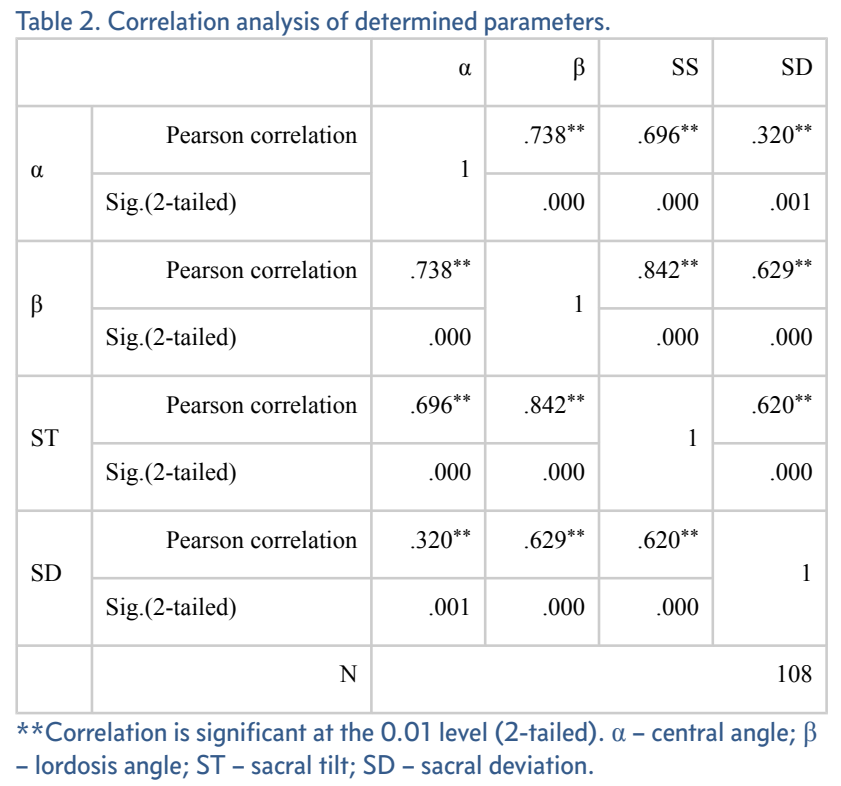

Table 3. Ranks and statistics of Mann-Whitney U-criteria for main and control groups.

\begin{tabular}{|c|c|c|c|c|c|c|c|c|c|c|c|c|c|c|c|c|c|}
\hline \multirow{3}{*}{$\alpha$} & Group & $\mathrm{N}$ & \multirow{2}{*}{$\begin{array}{c}\text { Mean } \\
\text { Rank } \\
61.77\end{array}$} & $\begin{array}{r}\text { Sum of } \\
\text { Ranks }\end{array}$ & $\begin{array}{r}\text { Mann- } \\
\text { Whitney } \\
\text { U }\end{array}$ & $\begin{array}{r}\text { Wilcoxon } \\
\text { W }\end{array}$ & $\mathrm{Z}$ & \multicolumn{10}{|c|}{$\begin{array}{l}\text { Asymp.Sig.(2-tailed) Table 5. Ranks and statistics of Mann-Whitney U-criteria for Ks, KI, and } \\
\text { LSB. }\end{array}$} \\
\hline & 1 & 59 & & 3644.50 & \multirow[t]{3}{*}{1016.50} & \multirow[t]{3}{*}{2241.50} & \multirow[t]{3}{*}{-2.647} & \multirow[t]{2}{*}{0.008} & & \multirow[t]{2}{*}{ Group } & \multirow[t]{2}{*}{$\mathrm{N}$} & \multirow[t]{2}{*}{$\begin{array}{l}\text { Mean } \\
\text { Rank }\end{array}$} & \multirow[t]{2}{*}{$\begin{array}{l}\text { Sum of } \\
\text { Ranks }\end{array}$} & \multirow[t]{2}{*}{$\begin{array}{l}\text { Mann- } \\
\text { Whitney } \\
\text { U }\end{array}$} & \multirow[t]{2}{*}{$\begin{array}{l}\text { Wilcoxon } \\
\text { W }\end{array}$} & \multirow[t]{2}{*}{ Z } & \multirow[t]{2}{*}{$\begin{array}{l}\text { Asymp. } \\
\text { Sig. } \\
\text { (2-tailed) }\end{array}$} \\
\hline & 2 & 49 & 45.74 & 2241.50 & & & & & & & & & & & & & \\
\hline \multirow{4}{*}{$\beta$} & & & & & & & & \multirow{4}{*}{0.325} & \multirow{3}{*}{$\mathrm{K}_{\mathrm{s}}$} & 1 & 59 & 62.00 & 3658.00 & \multirow{3}{*}{1003.00} & \multirow{3}{*}{2228.00} & \multirow{3}{*}{-2.732} & \multirow{3}{*}{0.006} \\
\hline & 1 & 59 & 51.80 & 3056.00 & \multirow{3}{*}{1286.00} & \multirow{3}{*}{3056.00} & \multirow{3}{*}{-0.984} & & & & & & & & & & \\
\hline & & & & & & & & & & 2 & 49 & 45.41 & 2228.00 & & & & \\
\hline & & & 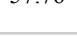 & 2030.00 & & & & & & 1 & 59 & 39.46 & 2328.00 & & & & \\
\hline & 1 & 59 & 54.44 & 3212.00 & & & & & $\mathrm{~K}_{1}$ & & & & & 558.00 & 2328.00 & -5.479 & 0.0001 \\
\hline ST & & & & & 1442.00 & 3212.00 & -0.022 & 0.983 & & 2 & 49 & 72.61 & 3558.00 & & & & \\
\hline & 2 & 49 & 54.57 & 2674.00 & & & & & & & & & & & & & \\
\hline & & & & & & & & & & 1 & 59 & 43.94 & 2592.50 & & & & \\
\hline & 1 & 59 & 44.62 & 2632.50 & & & & & LSB & & & & & 822.50 & 2592.50 & -3.846 & 0.0001 \\
\hline SD & & & & & 862.50 & 2632.50 & -3.598 & 0.000 & & 2 & 49 & 67.21 & 3293.50 & & & & \\
\hline & 2 & 49 & 66.40 & 3253.50 & & & & & & & & & & & & & \\
\hline & & & & & & & & & Total & & 108 & & & & & & \\
\hline Tota & & & & & & & & $\begin{array}{r}108 \\
\mathrm{~K}\end{array}$ & & al ( & & nt; K & umba & Deffic & LSB - L & & \\
\hline
\end{tabular}

Downloaded from http://ijssurgery.com/ by guest on April 26, 2023 number of researchers noted a high correlation between the angle of lumbar lordosis and orientation in space of the pelvis and thorax. ${ }^{14-16}$

One of the fundamental questions devoted to the evaluation of lumbar lordosis is the number of measured vertebral lumbar segments. Thus, Been et al. concluded, that most often all lumbar segments are measured (L1-L5), wherein an upper limit of the angle is the upper endplate of the L1 body, lower endplate of $\mathrm{S} 1$ body, but a number of researchers describe a technique for measuring from the T-10 segment; other authors may define L3 vertebra as the endpoint measurement or fail to include measurement of the lower lumbar segment or L5-S1 disc. ${ }^{17}$ Such differences cause the appearance of a significant difference in the published data dealing with the

\begin{tabular}{|c|c|c|c|c|c|c|c|}
\hline \multirow{2}{*}{\multicolumn{2}{|c|}{$\begin{array}{l}\text { Group } \\
\text { Parameter }\end{array}$}} & \multicolumn{3}{|r|}{ Main } & \multicolumn{3}{|c|}{ Control } \\
\hline & & $\mathrm{K}_{\mathrm{s}}$ & $\mathrm{K}_{1}$ & LSB & $\mathrm{K}_{\mathrm{s}}$ & $\mathrm{K}_{\mathrm{l}}$ & LSB \\
\hline \multicolumn{2}{|l|}{$\mathrm{N}$} & \multicolumn{3}{|r|}{59} & \multicolumn{3}{|r|}{49} \\
\hline \multicolumn{2}{|c|}{ Mean Std. Error } & 0.022 & 0.026 & 0.021 & 0.017 & 0.037 & 0.044 \\
\hline \multicolumn{2}{|l|}{ Median } & 0.90 & 0.86 & 0.18 & 0.77 & 1.11 & 0.34 \\
\hline \multicolumn{2}{|c|}{ Std. Deviation } & 0.167 & 0.199 & 0.163 & 0.118 & 0.260 & 0.307 \\
\hline \multicolumn{2}{|l|}{ Variance } & 0.028 & 0.040 & 0.026 & 0.014 & 0.068 & 0.094 \\
\hline \multirow{2}{*}{ Percentile } & 25 & 0.75 & 0.72 & 0.08 & 0.735 & 0.98 & 0.19 \\
\hline & 75 & 0.98 & 1.04 & 0.29 & 0.885 & 1.30 & 0.55 \\
\hline
\end{tabular}

$\mathrm{K}_{\mathrm{S}}$ - Sacral Coefficient; $\mathrm{K}_{\mathrm{l}}$ - Lumbar Coefficient; LSB - Lumbosacral Balance. 
measurement of lumbar lordosis. In our study, we used a standard method of measuring L1-L5 segments, as is anatomically reasonable and most commonly used. ${ }^{16-21}$ The five lumbar segments play a fundamental role in maintaining posture when upright. ${ }^{22}$ Also, many methods of the lordosis angle measuring on standard radiograms and MRI have been proposed. The Cobb method and its modifications are the gold standard to date. ${ }^{23}$ The method is very simple to perform and showed high reliability. We used the standard Cobb method in our study.

Different geometrical models of the spine have been proposed including arc of circle ${ }^{9,24,25}$ quadrant of an ellipse. ${ }^{26}$ The ellipsoid design is very realistic, but such difficult to use in everyday clinical practice ${ }^{27,28}$ because of difficulty in geometrical analysis of this model.

Several authors proposed geometric model of the lumbar spine, based on the assumption that lumbar lordosis is circular arcs segment. Vaz et al. ${ }^{10}$ proposed a method for modeling the sagittal curves of the spine by two tangents to the arc of a circle. The author presented vertebra curvatures (lumbar lordosis and thoracic kyphosis) as two circular tangent arcs whose tops are the thoracic kyphosis and the lumbar lordosis, respectively. The authors concluded that the method is useful for assessing the overall geometry of the spine, particularly in case of a limited view on radiographs. Pinel-Giroux et al. ${ }^{37}$ confirmed that the method is a good alternative to the Cobb angle and revealed a strong correlation between these two methods.

Roussouly et al. ${ }^{28}$ and Berthonnaud et al..$^{29}$ described a geometrical model of the lumbar biomechanics based on two tangent arcs of circle. In this approach lumbar lordosis is represented as two tangent arcs of a circle and placed the center of each arc on a horizontal line drawn from the apex. The lumbar curvature is therefore, divided into two tangent arcs of circle with the purpose of studying sagittal balance implications of each arc. The inferior arc extends from S1 to the apex, the upper arc from the apex to the inflexion point. The center of the inferior arc is located at the intersection of the horizontal line running from the apex and the line following the sacral plate; the radius of the upper arc is set by the line perpendicular to the tangent to the spinal curve at the level of the inflexion point (Figure 2).

The main disadvantage of the technique is the unclear mathematical basis. For example "apex" in this work is "most anterior point of the lumbar spine touches a vertical line." The functional purpose of this landmark is also unclear: "At this point, the curvature can be divided into two segments according to its position above or below the horizontal line crossing this point (the apex)." From geometrical point of view, there is no need of $\mathrm{C} 2$ circle, because value of lumbar lordosis as the segment of the circle, and as anatomical creation (lordosis angle) has direct relationship with angular values of the sacrum. In other words position of the sacrum in space determines a form of the lumbar curve as the unified geometrical system.

In our study we used geometrical model of the lumbar spine, when lumbar lordosis describes as only one circle, passing through the upper front angle of $\mathrm{L} 1$ vertebra and the upper front angle of $\mathrm{S} 1$ vertebra. Association geometrical circle parameters with anatomical landmarks allow us to construct circle arc in which the lumbar lordosis ideally matches. We also accounted the role of the sacrum in maintaining

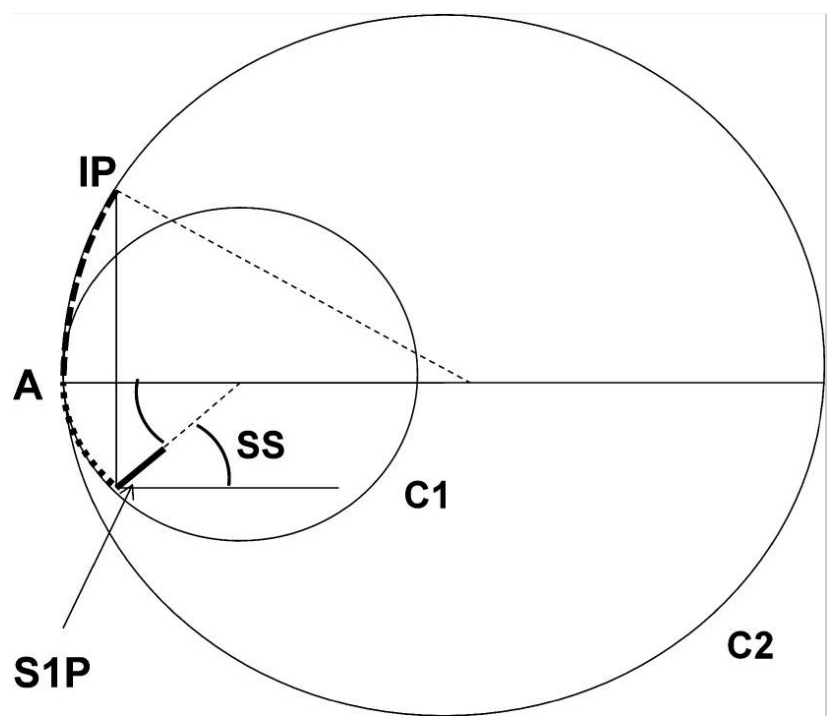

Fig. 2. Geometrical construct of Lumbar Lordosis (LL) by two tangent arcs of circle. LL is limited proximally by the Inflexion Point (IP) and distally by the sacral plateau (S1P). C1 and C2 are two tangent circles on the apex (A) of LL. LL is divided in two arcs; the upper one from IP to $A$ is located on C2, the lower between $\mathrm{A}$ and $\mathrm{S} 1 \mathrm{P}$ is on $\mathrm{C} 1$. As complementary angles, lower arc equals SS. 
lumbar curvature. But in our study we used a ratio (Sacral Coefficient) describes equilibrium position of the sacrum in a frame of reference in the sagittal plane. Relationship between lumbar curvature and sacrum position is also confirms by the correlation analyze presented in Table 2. Furthermore, we found clear mathematical relationship between angular parameters of lumbosacral spine, confirms by the proportionality of the changes in this angular values. This is the theme for our future publication.

Other important environment for the normal statics is the position of the sacrum, because Sacral Slope (SS) angle determines the shape of the lumbar lordosis arc. The first description of the geometrical parameters of the pelvis has been presented by DuvalBeaupère et al. ${ }^{31-33}$ Their studies allowed describe the geometry of the pelvis and the relationship of the geometric parameters of the pelvis with its space attitude. Key parameter of the pelvis is Pelvic incidence (PI), otherwise for describe the position of the sacrum in the horizontal axis Sacral Slope is used.

This conception actual for human upright position, but in our study all measurements were performed on supine MRI, as done in some of the other analogous studies. ${ }^{17,34,35}$ In recent years the MRI has become "gold standard" in diagnostic of the numerous pathological conditions of lumbar spine, including lumbar spinal stenosis, due to its possibility to visualize Roentgen-negative soft tissues. Standing MRI which was the alternative method to standing X-ray was not available in our center, so we chose the method of supine MRI. Recent investigations revealed that lumbar lordosis measured on horizontal MRI in supine position with straight legs was comparable to that measured on vertical standing images, ${ }^{22}$ and sagittal balance obtained in supine MRI is reliable for investigational studies. ${ }^{17}$

For this reason, for describe the location of the sacrum in the frame, we used two parameters: Sacral Tilt (ST) - as angle between upper endplate of S1 and vertical axis (analog Sacral Slope for the uptight position), and Sacral Deviation (SD) - angle between horizontal axis and the line from midpoint of the upper end plate of S1 to the ventral surface of the S1-S2 disc. This anatomical landmark is constant and well visualized either on the radiographs, or on the MRI. The frame axis designated on the basis of patient's supine position. Sacral Deviation (SD) showed significant correlation with anatomical and geometrical lumbo-sacral parameters (Table 2), moreover, significant differences has been found between main and control group in value of this parameter. This fact demonstrated its diagnostic and prognostic value in developing of degenerative changes of lumbar spine (Table 5).

The concept of lumbopelvic sagittal alignment that actively discuss in the literature recently, has been proposed by Duval-Beaupère et al. first. ${ }^{31}$ However, the valid method of quantitative assessment of lumbopelvic sagittal alignment is lacking. The goal of our study was a developing a simple, understandable and reliable method of quantitative assessment of lumbopelvic sagittal alignment. The method is based on evaluation of geometric and statistical regularities of the lumbar spine and sacrum, obtained from MRI in supine position. For each anatomical region the ratio of the couples of the angular values has been calculated: the ratio of the lordosis angle to the segmental angle for the lumbar spine (Lumbar coefficient), and the ratio of the Sacral Slope to Sacral Deviation for sacrum (Sacral coefficient). For quantitative assessment of lumbopelvic sagittal alignment we proposed parameter "lumbo-sacral balance" (LSB) - module of mathematical difference between Sacral and Lumbar coefficient.

In current study, we analyzed lumbosacral alignment for potential associations to lumbar spinal stenosis. Kirkaldy-Willis at al. ${ }^{36}$ studied the pathology and pathogenesis of lumbar spondylosis and stenosis and described the three-joint complex composed of the zygapophyseal joints and the intervertebral disc. They postulated that rotation and compression injuries led to degenerative changes of the three-joint complex. The results of these changes to the threejoint complex create degenerative spondylolisthesis, retrolisthesis, degenerative scoliosis, and rotational deformities. Approximately $90 \%$ of the population will report back pain, and the incidence of acquired lumbar stenosis is approximately 1 per 1000 in individuals older than 65 years. ${ }^{37}$ 
The relationship between lumbar lordosis and degenerative changes of the spine has been thoroughly evaluated..$^{3,58-43}$ Most researchers agree that the lumbar lordosis angle positively and strongly associated with spondylolysis and isthmic spondylolisthesis. ${ }^{5,38,44-47}$ Increasing of the lordosis angle is considered as a risk factor for progression of spondylolysis and ventral displacement of the affected vertebra.

A several researchers have reported that the change of lordosis curve and the spinal balance lead to early development of osteoarthritis and degeneration of the discs. ${ }^{48,49}$ However, the issue remains controversial. For example, two studies have examined the relationship between the lordosis angle and osteoarthritis of the facet joints in the population of Greeks and Americans. ${ }^{17,42}$ No statistically significant differences between the lordosis angle and osteoarthritis have been identified. Similar results were obtained by Lin et al..$^{39}$ in the Chinese population. These data show that the amount of lumbar lordosis is either a consequence, or reason for the development of osteoarthritis of the facet joints.

In our study we compared 2 groups of patients: with lumbar spinal stenosis (main group) and healthy volunteers (control group) in value of $\mathrm{K}_{\mathrm{s}}, \mathrm{K}_{\mathrm{l}}$ and LSB parameters (Table 4), and we found statistical significant differences among them (Table 5). As one can see from Table 4, the median of LSB value in main group is 0.18 (vs 0.34 in control group). The value of LSB less than 0.19 observed in $64.4 \%$ of cases ( 38 out of 59) in main group vs $26.53 \%$ (13 out of 49 ) in control group. Figure 3 is an example of lumbosacral balance calculations in patient with lumbar spinal stenosis, and Figure 4 shows the calculations in healthy volunteer.

Based on these results we believe that that spinal stenosis is associated with an acquired deformity that is measureable by the described parameters. It's possible that spinal stenosis occurs in patients with an LSB of 0.20 or less, so this value can be predictable for its development. It may suggest that spinal stenosis is more likely to occur in patients with the spinal curvature of this type because of abnormal distribution of the spine loads. This fact may have prognostic significance for develop vertebral column disease and evaluation of treatment results.

\section{Conclusion}

In this study we proposed new method for assessment lumbosacral sagittal alignment in supine MRI. Method based on assumption that geometry of the lumbar lordosis is similar to the geometry of the cir-

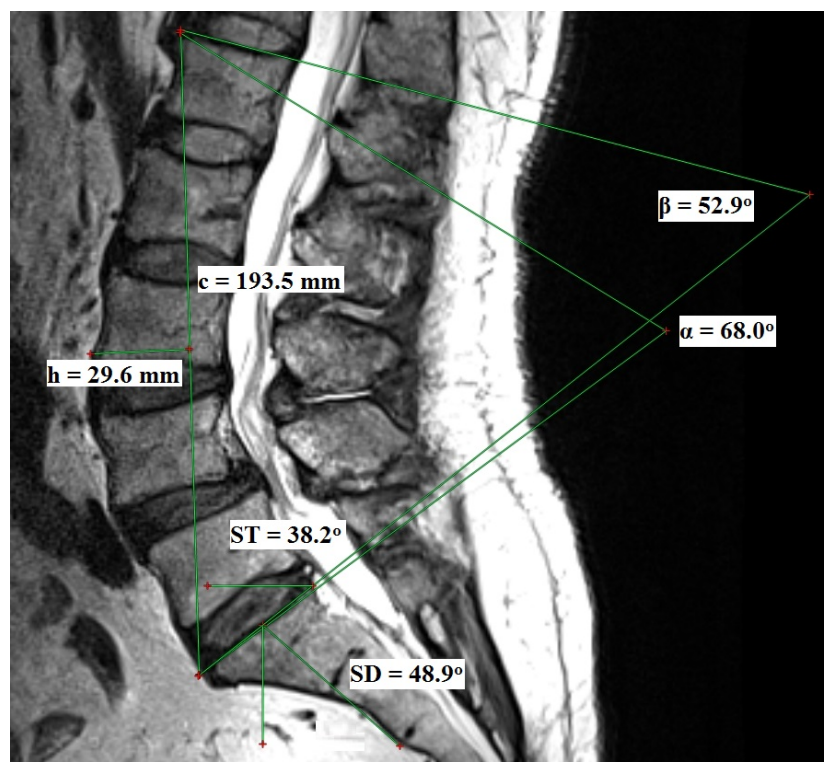

Fig. 3. Geometry of the lumbar lordosis arc at patients with lumbar spinal stenosis. Sacral coefficient $\left(\mathrm{K}_{\mathrm{S}}\right)=0.78$; Lumbar coefficient $\left(\mathrm{K}_{\mathrm{l}}\right)=0.77$; Lumbosacral balance $(\mathrm{LSB})=0.01$. $\mathrm{L}$ - circle arc length; $\alpha$ - central angle; $\beta$ - lordosis angle; $c$ - chord length; $r$ - circle radius; $h$ - segment height. ST - sacral tilt. SD - sacral deviation.

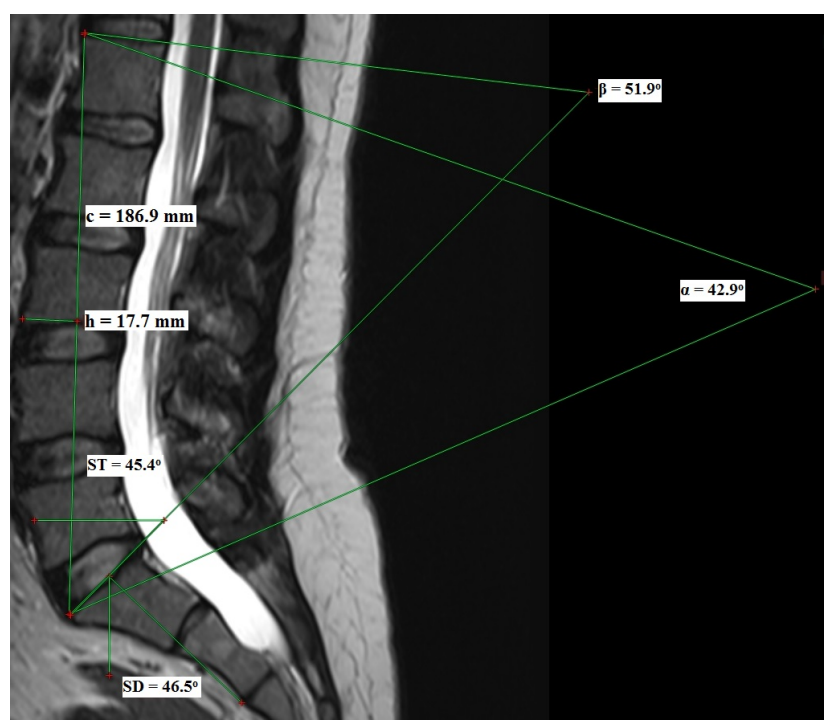

Fig. 4. Geometry of the lumbar lordosis arc in healthy volunteer. Sacral coefficient $\left(\mathrm{K}_{\mathrm{S}}\right)=0.98$; Lumbar coefficient $\left(\mathrm{K}_{\mathrm{I}}\right)=1.21$; Lumbosacral balance $(\mathrm{LSB})=0.23$. $\mathrm{L}-$ circle arc length; $\alpha-$ central angle; $\beta$ - lordosis angle; $c$ - chord length; $r$ - circle radius; $h$ - segment height. ST - sacral tilt; $\mathrm{SD}$ - sacral deviation. 
cle arc. This assumption it was proved geometrically. Based on coefficients of angular values we proposed new parameter LSB for to quantifying lumbosacral sagittal balance. Comparing 2 groups of patients with spinal stenosis and without a history spine disorders show statistical significant differences in the LSB parameter. The results of this study are encouraging.

However, further researches are necessary with supine and upright position for assessment sensitivity and specificity of proposed method. We found clear mathematical relationship between angular parameters of lumbosacral spine, confirmed by the proportionality of the changes in this angular values. We plan to undertake a similar study with patients after operative treatment to assess the prognostic value of the technique for long-term complications associated with biomechanical disturbance (adjacent syndrome disease).

\section{References}

1. Legaye Jean (2011). Analysis of the Dynamic Sagittal Balance of the Lumbo-Pelvi-Femoral Complex, Biomechanics in Applications, Dr Vaclav Klika (Ed.), ISBN: 978-953-307-969-1, InTech, DOI: 10.5772/19608.

2. Adams MA, Mannion AF, Dolan P. Personal risk factors for first time low back pain. Spine 1999;24:2497-505.

3. Berlemann U, Jeszenszky DJ, Buhler DW, Harms $\mathrm{J}$. The role of lumbar lordosis, vertebral end-plate inclination, disc height, and facet orientation in degenerative spondylolisthesis. J Spinal Disord 1999;12:68-73.

4. Booth KC, Bridwell KH, Lenke LG, et al. Complications and predictive factors for the successful treatment of flatback deformity (fixed sagittal imbalance). Spine 1999;24:1712-20.

5. Chen IR, Wei TS. Disc height and lumbar index as independent predictors of degenerative spondylolisthesis in middle-aged women with low back pain. Spine 2009;34:1402-9.

6. Jang JS, Lee SH, Min JH, Maeng DH. Influence of lumbar lordosis restoration on thoracic curve and sagittal position in lumbar degenerative kyphosis patients. Spine 2009;34:280-4.
7. Giglio CA, Volpon JB. Development and evaluation of thoracic kyphosis and lumbar lordosis during growth. J Child Orthop 2007;1:187-93.

8. Mac-Thiong JM, Labelle H, Berthonnaud E, et al. Sagittal spinopelvic balance in normal children and adolescents. Eur Spine J2007;16:227-34.

9. Claus AP, Hides JA, Moseley GL, Hodges PW. Different ways to balance the spine: subtle changes in sagittal spinal curves affect regional muscle activity. Spine 2009;34:E208-14.

10. Vaz G, Roussouly P, Berthonnaud E, Dimnet J. Sagittal morphology and equilibrium of pelvis and spine. Eur Spine J 2002;11:80-7.

11. Vialle R, Levassor N, Rillardon L, et al. Radiographic analysis of the sagittal alignment and balance of the spine in asymptomatic subjects. J Bone Joint Surg Am 2005;87:260-7.

12. Been E, Barash A, Pessah H, Peleg S. A new look at the geometry of the lumbar spine. Spine 2010;35:E1014-7.

13. Cheng XG, Sun Y, Boonen S, et al. Measurements of vertebral shape by radiographic morphometry: sex differences and relationships with vertebral level and lumbar lordosis. Skeletal Radiol 1998;27:380-4.

14. Roussouly P, Nnadi C. Sagittal plane deformity: an overview of interpretation and management. Eur Spine J 2010;19:1824-36.

15. Schwab F, Patel A, Ungar B, et al. Adult spinal deformity postoperative standing imbalance: how much can you tolerate? An overview of key parameters in assessing alignment and planning corrective surgery. Spine 2010;35:2224-31.

16. Ostrowska B, Rozek-Mroz K, Giemza C. Body posture in elderly, physically active males. Aging Male 2003;6:222-9.

17. Kalichman L, Li L, Hunter DJ, Been E. Association between computed tomography-evaluated lumbar lordosis and features of spinal degeneration, evaluated in supine position. Spine J 2011;11:308-15.

18. Kumar MN, Baklanov A, Chopin D. Correlation between sagittal plane changes and adjacent segment degeneration following lumbar spine fusion. Eur Spine J 2001;10:314-9.

19. Been E., Kalichman L. Lumbar lordosis. Spine Journal 2013;14:87-97.

20. Cil A, Yazici M, Uzumcugil A, et al. The evolu-

Downloaded from http://ijssurgery.com/ by guest on April 26, 2023 
tion of sagittal segmental alignment of the spine during childhood. Spine 2005;30:93-100.

21. Suzuki H, Endo K, Kobayashi H, et al. Total sagittal spinal alignment in patients with lumbar canal stenosis accompanied by intermittent claudication. Spine 2010;35:E344-6.

22. Andreasen ML, Langhoff L, Jensen TS, Albert HB. Reproduction of the lumbar lordosis: a comparison of standing radiographs versus supine magnetic resonance imaging obtained with straightened lower extremities. J Manipulative Physiol Ther 2007;30:26-30.

23. Gracovetsky SA, Zeman V, Carbone AR. Relationship between lordosis and the position of the centre of reaction of the spinal disc. J Biomed Eng 1987;9:237-48.

24. Vrtovec T, Pernus F, Likar B. A review of methods for quantitative evaluation of spinal curvature.

Eur Spine J 2009;18:593-607

25. Pinel-Giroux FM, Mac-Thiong JM, de Guise J, Berthonnaud E, Labelle H (2006) Computerized assessment of sagittal curvatures of the spine: comparison between Cobb and tangent circles techniques. J Spinal Disord Tech 19:507-512.

26. Janik TJ, Harrison DD, Cailliet R, Troyanovich SJ, Harrison DE. Can the sagittal lumbar curvature be closely approximated by an ellipse? J Orthop Res. 1998 Nov; 16(6):766-70.

27. Barrey C (2004) Equilibre sagittal pelvirachidien et pathologies lombaires dégénératives. Etude comparative à propos de 100 cas. Thèse Doctorat-Université Claude-Bernard, Lyon 1 (in French)

28. Roussouly P, Pinheiro-Franco JL. Sagittal parameters of the spine: biomechanical approach. European Spine Journal. 2011;20(Suppl 5):578-585.

29. Berthonnaud E, Dimnet J (2007) Analysis of structural features of deformed spines in frontal and sagittal projections. Comput Med Imaging Graph 31:9-16.

30. Pinel-Giroux FM, Mac-Thiong JM, de Guise J, Berthonnaud E, Labelle H (2006) Computerized assessment of sagittal curvatures of the spine: comparison between Cobb and tangent circles techniques. J Spinal Disord Tech 19:507-512.

31. Duval-Beaupère G, Schmidt C, Cosson $P$ (1992)

A Barycentremetric study of the sagittal shape of spine and pelvis: the conditions required for an economic standing position. Ann Biomed Eng

20:451-462

32. Duval-Beaupère G, Legaye J (2004) Composante sagittale de la statique rachidienne. Rev Rhum 71:105-119

33. Boulay C, Tardieu C, Hecquet J, Benaim C, Mouilleseaux B, Marty C, Prat-Pradal D, Legaye J, Duval-Beaupère G, Pélissier J (2006) Sagittal alignment of spine and pelvis regulated by pelvic incidence: standard values and prediction of lordosis. Eur Spine J 15(4):415-422

34. Ergun T, Lakadamyali H, Sahin MS. The relation between sagittal morphology of the lumbosacral spine and the degree of lumbar intervertebral disc degeneration. Acta Orthop Traumatol Turc 2010;44:293-299.

35. Habibi Z, Maleki F, Meybodi AT, Mahdavi A, Saberi H. Lumbosacral Sagittal Alignment in Association to Intervertebral Disc Diseases. Asian Spine J. 2014 Dec;8(6):813-819.

36. Kirkaldy-Willis WH, Wedge JH, Yong-Hing K. Pathology and pathogenesis of lumbar spondylolisthesis and stenosis. Spine 1978;3:319-28.

37. Hakelius A. Prognosis in sciatica: a clinical follow-up of surgical and non-surgical treatment. Acta Orthop Scand 1970;(Suppl 129):1-76.

38. Mazanec DJ. Back pain: medical evaluation and therapy. Cleve Clin J Med 1995;62:163-8.

39. Schuller S, Charles YP, Steib JP. Sagittal spinopelvic alignment and body mass index in patients with degenerative spondylolisthesis. Eur Spine J 2011;20:713-9.

40. Lin RM, Jou IM, Yu CY. Lumbar lordosis: normal adults. J Formos Med Assoc 1992;91:329-33

41. Harrison DD, Cailliet R, Janik TJ, et al. Elliptical modeling of the sagittal lumbar lordosis and segmental rotation angles as a method to discriminate between normal and low back pain subjects. J Spinal Disord 1998;11:430-9.

42. Lebkowski WJ, Lebkowska U, Niedzwiecka M, Dzieciol J. The radiological symptoms of lumbar disc herniation and degenerative changes of the lumbar intervertebral discs. Med Sci Monit 2004;10(3 Suppl):112-4.

43. Papadakis M, Papadokostakis G, Kampanis N, et al. The association of spinal osteoarthritis with 
lumbar lordosis. BMC Musculoskelet Disord 2010;11:1.

44. Rosenberg NJ. Degenerative spondylolisthesis. Predisposing factors. J Bone Joint Surg Am 1975;57:467-74.

45. Antoniades SB, Hammerberg KW, DeWald RL. Sagittal plane configuration of the sacrum in spondylolisthesis. Spine 2000;25:1085-91.

46. Been E, Li L, Hunter DJ, Kalichman L. Geometry of the vertebral bodies and the intervertebral discs in lumbar segments adjacent to spondylolysis and spondylolisthesis: pilot study. Eur Spine J 2011;20:1159-65.

47. Huang KY, Lin RM, Lee YL, Li JD. Factors affecting disability and physical function in degenerative lumbar spondylolisthesis of L4-5: evaluation with axially loaded MRI. Eur Spine J 2009;18:1851-7. 48. Labelle H, Roussouly P, Chopin D, et al. Spinopelvic alignment after surgical correction for developmental spondylolisthesis. Eur Spine J 2008;17:1170-6.

49. Umehara $S$, Zindrick MR, Patwardhan AG, et al. The biomechanical effect of postoperative hy- polordosis in instrumented lumbar fusion on instrumented and adjacent spinal segments. Spine 2000;25:1617-24.

50. Kumar MN, Baklanov A, Chopin D. Correlation between sagittal plane changes and adjacent segment degeneration following lumbar spine fusion. Eur Spine J 2001;10:314-9.

\section{Disclosures}

The authors declare no relevant disclosures.

\section{Corresponding Author}

Andrew Yuz, MD, RMAPE, Moscow, Russia. worfeva@gmail.com.

Published 2 December 2015.

This manuscript is generously published free of charge by ISASS, the International Society for the Advancement of Spine Surgery. Copyright @ 2015 ISASS. To see more or order reprints or permissions, see http://ijssurgery.com. 